\title{
Ifluence of Yarn Texturing Technological Parameters and Fabric Structure on Tensile Properties of the Polipropylene Fabric
}

\author{
Raimundas ABROMAVIČIUS * , Ginta LAURECKIENĖ, Rimvydas MILAŠIUS \\ Department of Textile Technology, Kaunas University of Technology, Studentu str. 56, LT-51424 Kaunas, Lithuania, \\ Received 27 December 2010; accepted 25 May 2011
}

\begin{abstract}
Tensile properties of the woven fabric are very important properties for upholstered furniture manufacturers. In this study the dependencies of tensile properties of the fabric on yarn air texturing parameters and fabric structure were investigated. It was found, that breaking force and elongation at break depends more on yarn structure, than on air pressure in the texturing jet. The difference of fabric elongation at break does not exceed $2 \%$ and difference of fabric breaking force does not exceed $5 \%$ when yarns of the same structure but produced with different air pressure in the texturing jet were used in weft. In the case when different structure yarn produced with same pressure in the texturing jet were used in weft, there were difference of breaking force and elongation at break up to $25 \%$ stated. There were also investigated tendencies of tensile properties of fabric dependencies on fabric structure itself. It was stated that weave of the fabric influences elongation at break and breaking force of the fabric.
\end{abstract}

Keywords: air textured yarn, woven fabrics, tensile properties of the fabrics.

\section{INTRODUCTION}

There are many different fabrics used for upholstered furniture. In upholstered furniture it is very important to use fabrics with high quality tensile properties, such as elongation, breaking force, shearing.

It is known, that main parameters, which have influence on fabric tensile properties, are set and weave of the fabric, linear densities of yarns, yarn structure, twist, raw material.

There are some works made on yarn properties strength influence on fabric tensile properties. Seo [1] et all have investigated mechanical properties of fabrics woven from yarns produced by different spinning technologies. Similar research had been carried out earlier by Lord and Radhakrishnaiah [2]. Frydrich, Dziworska and Matusiak [3] have studied influence of yarn properties on strength properties of the fabric. In all these works there were stated that breaking force and elongation at break of a fabric are in close relation to the tensile properties of the yarn [4]. There is no doubt, that the tensile properties of the yarn are the starting point, but there are also other factors which have effect on strength and elasticity of the fabric. One of these factors is structure of the fabric itself. And there are many different proposals, how to estimate influence of fabric structure. Brierley [5], Peirce [6], Galceran [7], Newton [8], Milašius [9] have elaborated different integrated fabric structure factors, which are based on linear density of yarns, density of warp and weft, and weave of the fabric. Nikolic et all [10] suggested to estimate a fabric strength as a function of yarn strength, fabric density and yarn strength coefficient. The most recently was developed integrated fabric structure factor by Milašius, which is taking into account weave matrix. Influence of weave matrix is estimated by weave factor $P$. In later works of $\mathrm{V}$. Milašius and A. Milašius [11] there were proposed factors

\footnotetext{
*Corresponding author Tel.: +370-698-77425; fax: +370-37-353989 E-mail address: raimundas.abromavicius@stud.ktu.lt (R. Abromavičius)
}

$P_{a}, P_{m}$ and $P^{\prime}$, which are modifications of $P$, according to a direction of weft $\left(P_{a}\right)$, warp $\left(P_{m}\right)$, and one for unbalanced weaves $\left(P^{\prime}\right)$. There were some experimental investigations made by Milašius et all [12], E. Kumpikaitė [13-15] and others made in order to check how this integrated factor correlates with tensile properties of the fabric woven from yarn produced by traditional spinning technologies.

The aim of this paper is to show, that the properties of textured yarn influences tensile properties of the fabric in the same way as properties of yarn produced by traditional spinning techniques, and that the integrated fabric structure factor proposed by Milašius is also correlating with tensile properties of the fabrics woven from textured yarn.

\section{MATERIALS AND METHODS}

In order to study the influence of various structures of the yarn and such technological parameters as air pressure in the texturing jet on properties of the fabric woven from these yarns, some samples of yarn were produced and some samples of fabrics weaved. Yarn samples were made from 33 tex multifilament polypropylene yarns containing 72 filaments each. The same filament yarns were used as core and effect yarns. Polypropylene was chosen due to its high importance for upholstery manufacturing. To produce textured yarn, an SSM RMT-D air texturing machine with a Hemajet-LB04 texturing jet was used [16].

Three different sample yarns were produced (see Table 1.

Table 1. Yarn production parameters

\begin{tabular}{|c|c|c|}
\hline Yarn & Structure* $^{*}$ & Pressure, MPa \\
\hline S7 & $1 \mathrm{c}+3 \mathrm{e}$ & 0.6 \\
\hline S9 & $3 \mathrm{c}+1 \mathrm{e}$ & 0.8 \\
\hline S11 & $3 \mathrm{c}+1 \mathrm{e}$ & 0.6 \\
\hline
\end{tabular}

$*_{\mathrm{c}}$ - number of core yarns, $\mathrm{e}-$ number of effect yarns.

Overfeeding of core yarn was constant $-11 \%$. The overfeeding of the effect yarn was also constant $-43 \%$. 
The winding speed was $209.5 \mathrm{~m} / \mathrm{min}$, the same for all samples. The yarn linear density was determined using a Zweigle L 232 reeling machine and Branca Idealair Mark 160 scale. To determine the linear density of the yarn, 5 specimens of $100 \mathrm{~m}$ yarn length were prepared, from which an average value was taken [17].

It is clear, that the properties of air-jet textured yarns are affected by air pressure, overfeed, and different overfeed levels of the core and effect components [16]. To observe the influence of texturing parameters and fabric structure on fabric tensile properties there were two different weaving tests carried out.

For the first test there were plain weave fabric with yarn of the same structure, but produced with different texturing air pressure, in weft weaved. There were four samples with yarn S9 and four samples with yarn S11 in weft and different set of the weft weaved on a Somet Thema11 rapier weaving loom.Density of warp was $7 \mathrm{~cm}^{-1}$, density of weft was changing from $6.5 \mathrm{~cm}^{-1}$ to $8 \mathrm{~cm}^{-1}$ by steps of $0.5 \mathrm{~cm}^{-1}$.

For the second test there were four samples of different weave fabrics with different structure yarn (S7 and S11) in weft woven on the same loom. The weaves were twill 2/1 (R2/1), basket weave 2/2 (P2/2), weft rib 2/2 (AR2), warp rib 2/2 (MR2). Warp set was $7 \mathrm{~cm}^{-1}$, and weft set was $6.5 \mathrm{~cm}^{-1}$. For all samples the same warp were used. All samples were woven under the same conditions.

Table 2. Weave factor values

\begin{tabular}{|c|c|c|c|c|}
\hline & $\mathrm{R} 2 / 1$ & $\mathrm{P} 2 / 2$ & $\mathrm{AR} 2 / 2$ & $\mathrm{MR} 2 / 2$ \\
\hline$P$ & 1.155 & 1.359 & 1.118 & 1.249 \\
\hline$P^{\prime}$ & 1.155 & 1.359 & 1.000 & 1.309 \\
\hline$P_{a}$ & 1.155 & 1.359 & 1.309 & 1.000 \\
\hline$P_{m}$ & 1.155 & 1.359 & 1.124 & 1.124 \\
\hline
\end{tabular}

Tensile tests according to standard ISO 13934-1 [19] from all samples of fabric were made on a Zwick tensile tester.

\section{RESULTS AND DISCUSSIONS}

Tensile tests of the fabrics from first weaving tests showed that air pressure in the texturing jet, when there were weft yarn samples produced, had no significant influence on the fabric tensile properties such as breaking force and elongation at break (see Fig. 1 and Fig. 2). The fabric breaking force difference because of air pressure in the yarn texturing jet is less than $5 \%$ and difference of elongation because of pressure in the texturing jet is less than $2 \%$ between fabrics with yarn S9 and S11 in weft. Such difference is in the limits of error.

Weft density has great influence on strength and elongation at break of the fabric. This influence can be described by linear equation (coefficients of determination are very high $-R^{2}=0.8731 \div 0.992$ ).

Next set of tensile tests was made from fabrics of the different weaves woven with yarn S7 and S11 in the weft. Results of these tests showed that there is significant influence of weft yarn structure on fabric tensile properties in weft direction. Average difference of breaking force and elongation at break is approximately $17 \%$. In some fabrics (warp rib2/2) this difference is reaching more than $25 \%$ (see Fig. 3 and Fig. 4). It is necessary to note, that these tendencies are the same for all weaves used.

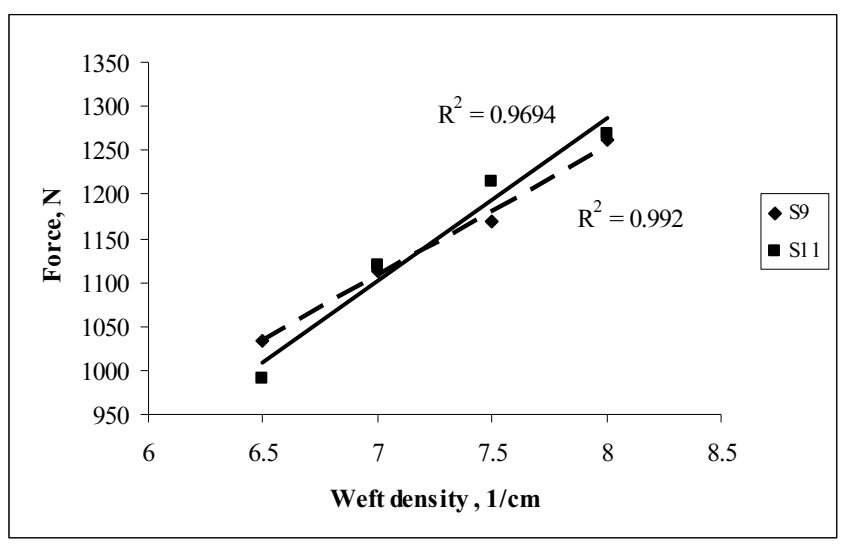

Fig. 1. Dependences of breaking force of the fabric with yarn S9 and S11 in weft

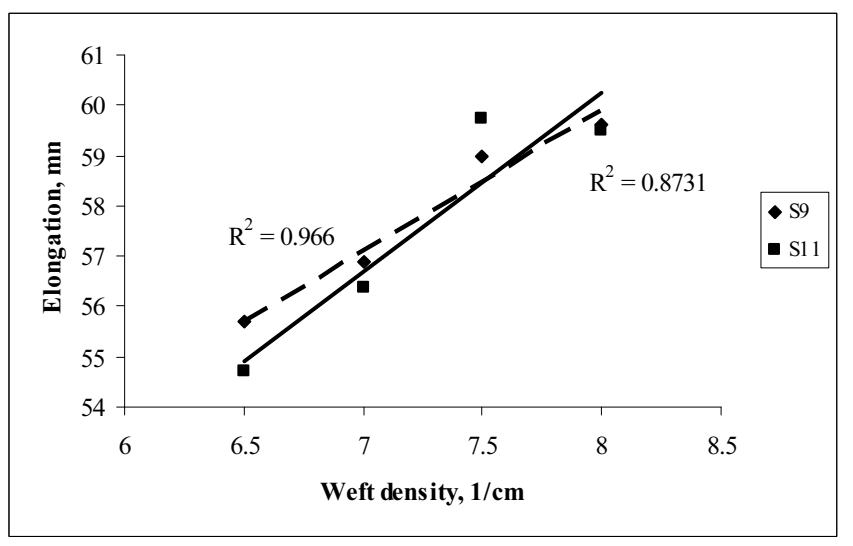

Fig. 2. Dependences of elongation at break of the fabric with yarn S9 and S11 in weft

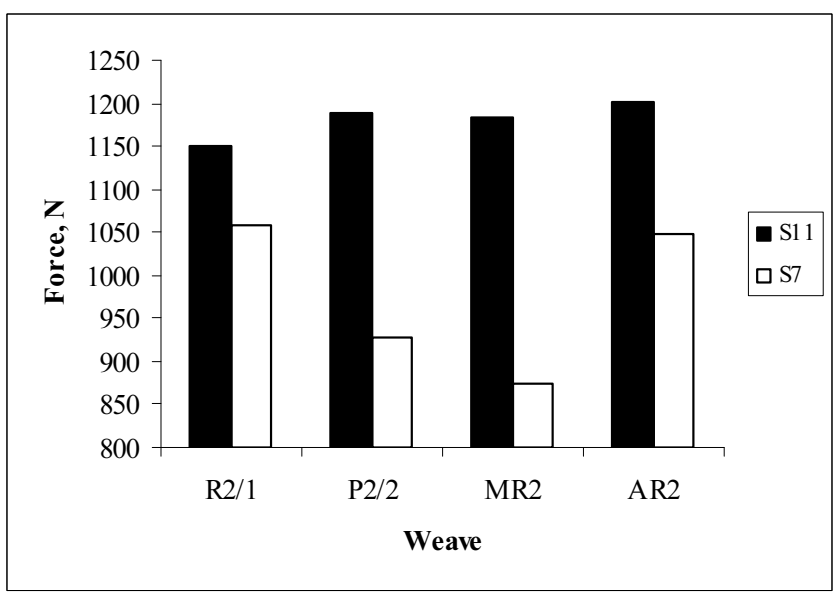

Fig. 3. Differences of breaking force of the fabrics with yarn S7 and S11 in weft

In order to investigate dependencies of tensile properties of the fabric on such structural parameters as weave factors $P, P^{\prime}, P_{a}$ and $P_{m}$ there were tensile tests in warp and weft direction made. Results of tests in warp direction showed, that weave has more influence on 
elongation at break, than on breaking force. Difference between maximum and minimum values of elongation of fabrics with S7 and S11 yarn in weft is $37 \%-38 \%$, when difference between maximum and minimum values of breaking force is $12 \%$ with yarn S11 and $8 \%$ with yarn S7 in weft (See Fig. $5 \div$ Fig. 12).

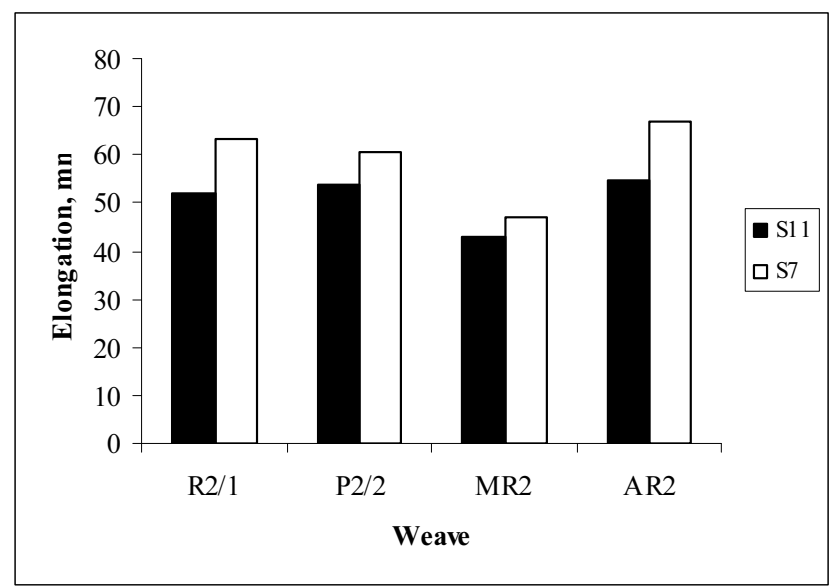

Fig. 4. Differences of elongation at break of the fabrics with yarn S7 and S11 in weft

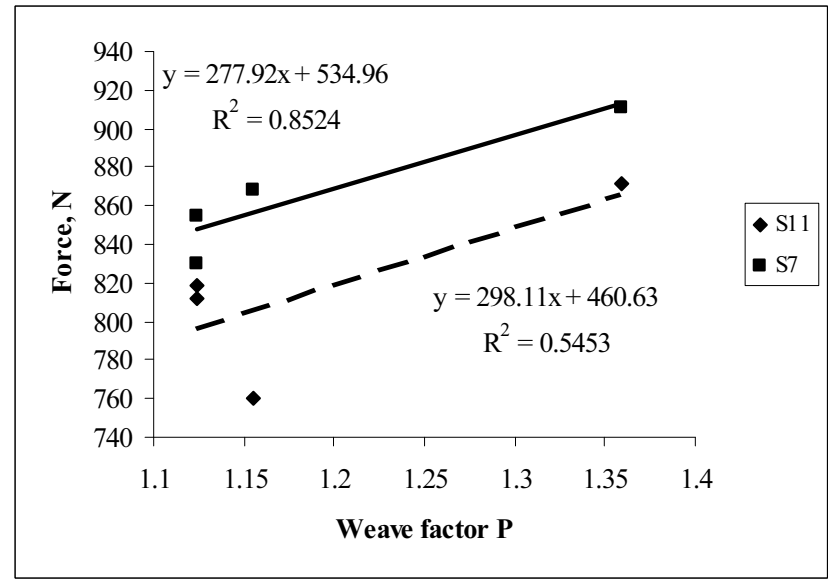

Fig. 5. Dependence of breaking force on weaving factor $P$ in warp direction

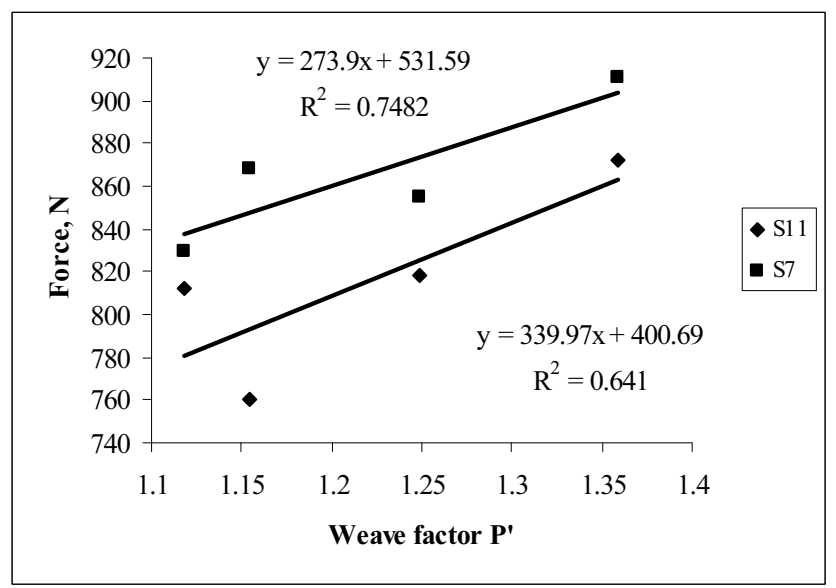

Fig. 6. Dependence of breaking force on weaving factor $P^{\prime}$ in warp direction

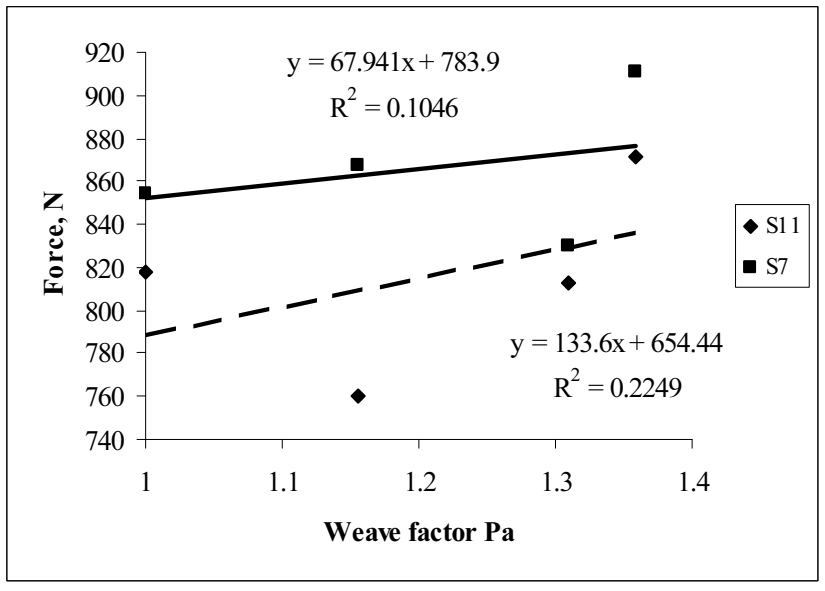

Fig. 7. Dependence of breaking force on weaving factor $P_{a}$ in warp direction

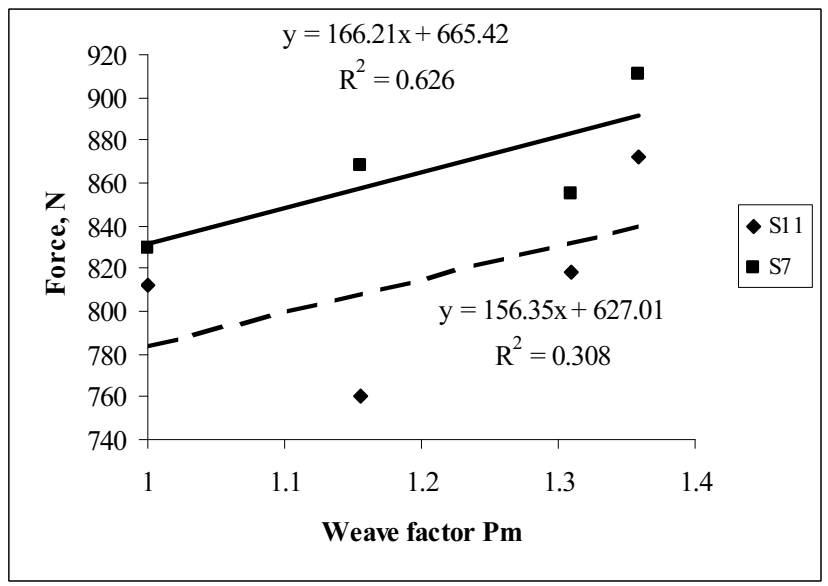

Fig. 8. Dependence of breaking force on weaving factor $P_{m}$ in warp direction

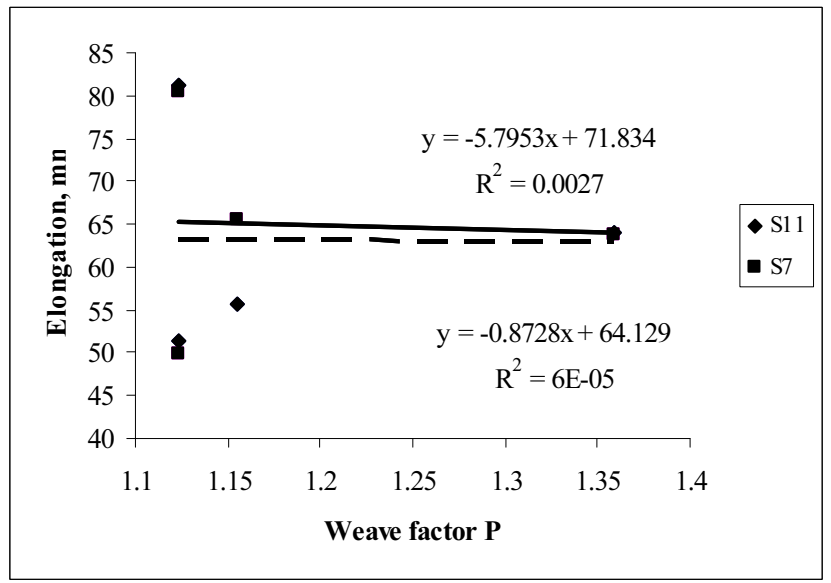

Fig. 9. Dependence of elongation on weaving factor $P$ in warp direction

As we can see from diagrams, highest correlation of breaking force in warp direction is with weave factors $P$ and $P^{\prime}$, when in case of elongation, the best correlation is with weave factors $P_{a}$ and $P_{m}$. Determination coefficients of empiric equations of breaking force and elongation dependencies on weave factors are low. Determination coefficients of functions of breaking force dependence on 
weave factor $P$ is 0.85 in case of yarn $\mathrm{S} 7$ in weft and 0.54 in case of yarn S11 in weft (see Fig. 5). Determination coefficients of equation of breaking force dependence on $P^{\prime}$ are varying from 0.64 in case of yarn S11 up to 0.74 in case of yarn S7 in weft (see Fig. 6). These weave factors can not be used to determine dependence of fabric tensile properties on weave, because there are cases, where visible

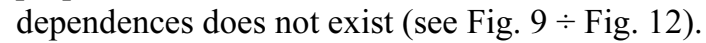

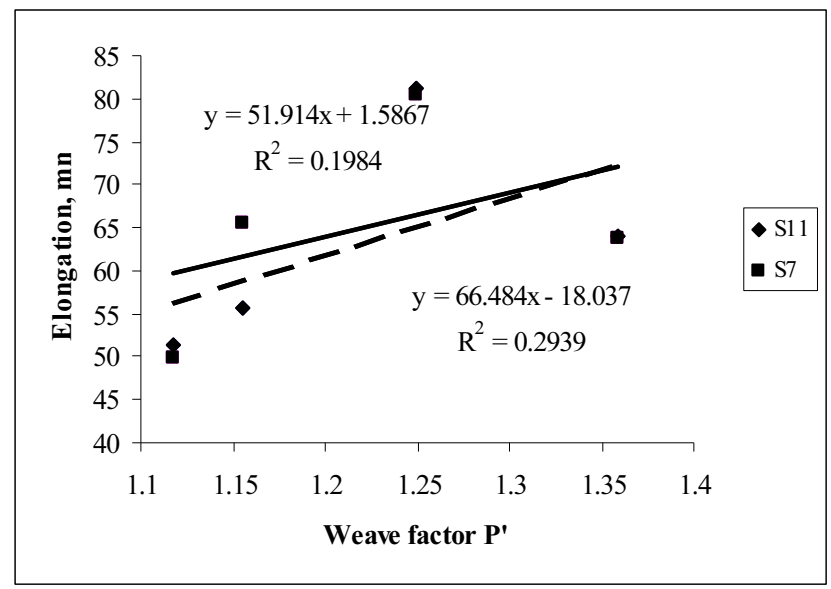

Fig. 10. Dependence of elongation on weaving factor $P^{\prime}$ 'in warp direction

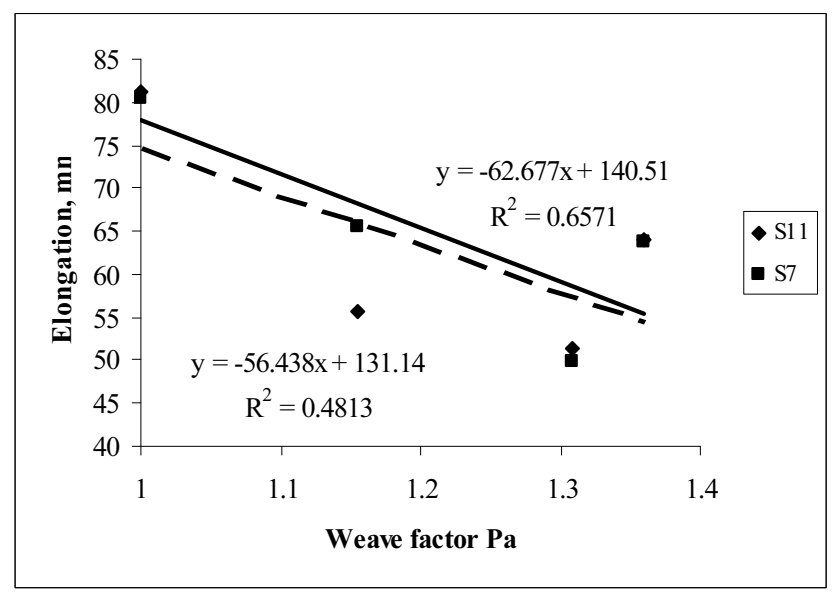

Fig. 11. Dependence of elongation on weaving factor $P_{a}$ in warp direction

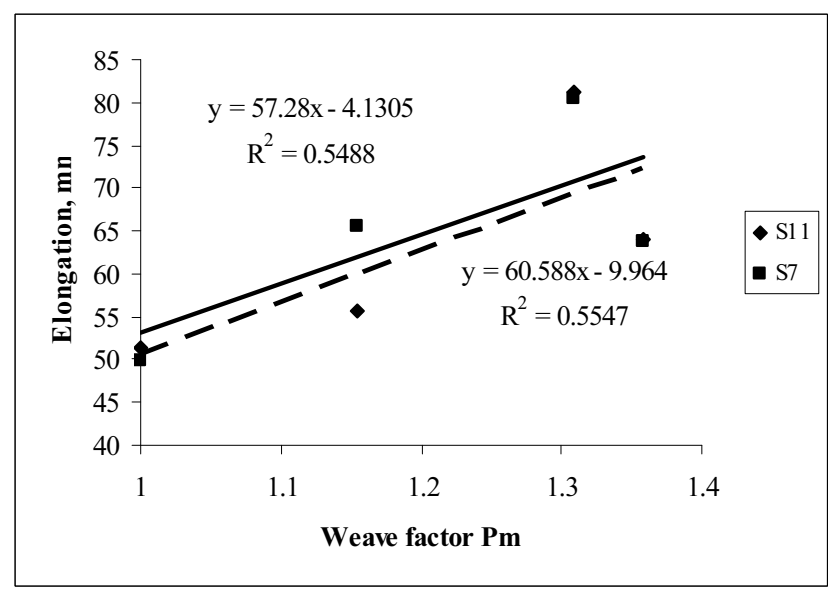

Fig. 12. Dependence of elongation on weaving factor $P_{m}$ in warp direction
Regarding elongation dependencies, highest determination coefficient was achieved with equations of elongation dependences on weave factors $P_{a}$ and $P_{m}$, but they have not exceeded 0.7 .

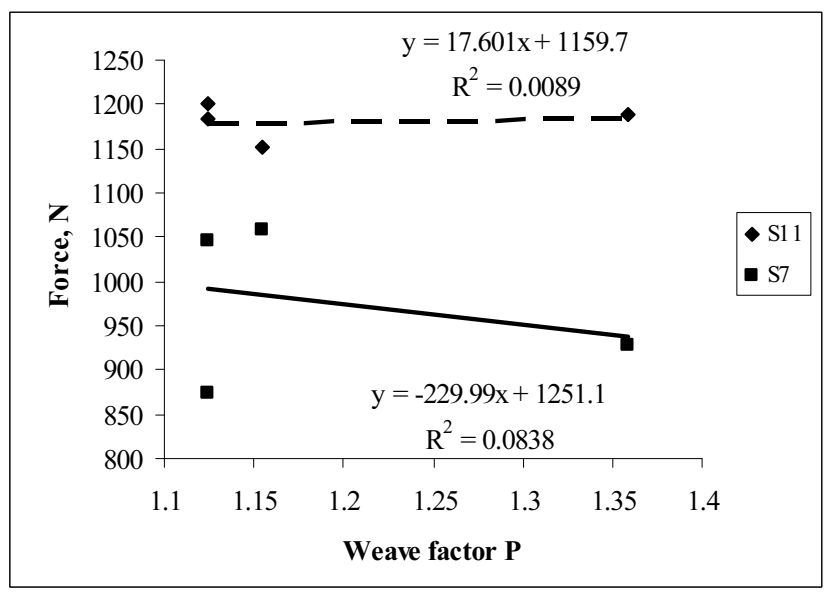

Fig. 13. Dependence of breaking force on weaving factor $P$ in weft direction

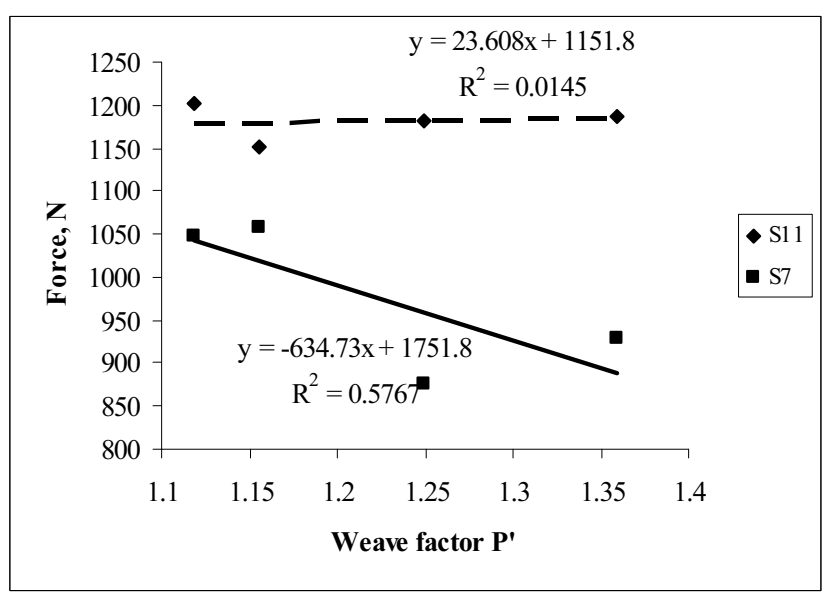

Fig. 14. Dependence of breaking force on weaving factor $P^{\prime}$ in weft direction

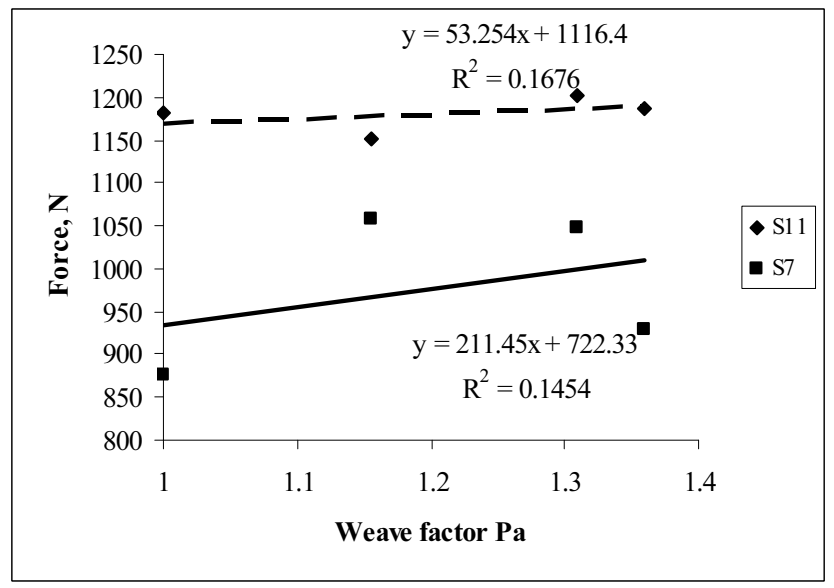

Fig. 15. Dependence of breaking force on weaving factor $P_{a}$ in weft direction

Tensile tests in weft direction gave some unexpected results. The value of breaking force in case of yarn S11 in weft remained quit constant (difference between minimum 
and maximum values is just $4 \%$ ), when in case of yarn S7 in weft we can see a difference between minimum and maximum values around $17 \%$ (See Fig. $13 \div$ Fig. 16). This can be explained by yarn structure differences. In yarn S11 there are 3 core yarns and just one effect yarn, when in yarn S7 we have just 1 core yarn and 3 effect yarns. The stress in case of yarn S11 is distributed on 3 core yarns comparing to 1 core yarn in case of yarn S7. Also the surface of yarn S11 is more even than surface of yarn S7, that means there are less friction between warp and weft in case of yarn S11. Because of these two reasons influence of weave on breaking force is not significant in case of yarn S11 in weft. Highest determination coefficient of breaking force dependence on weave factor was achieved in case of yarn S7 and weave factor $P_{m}$.

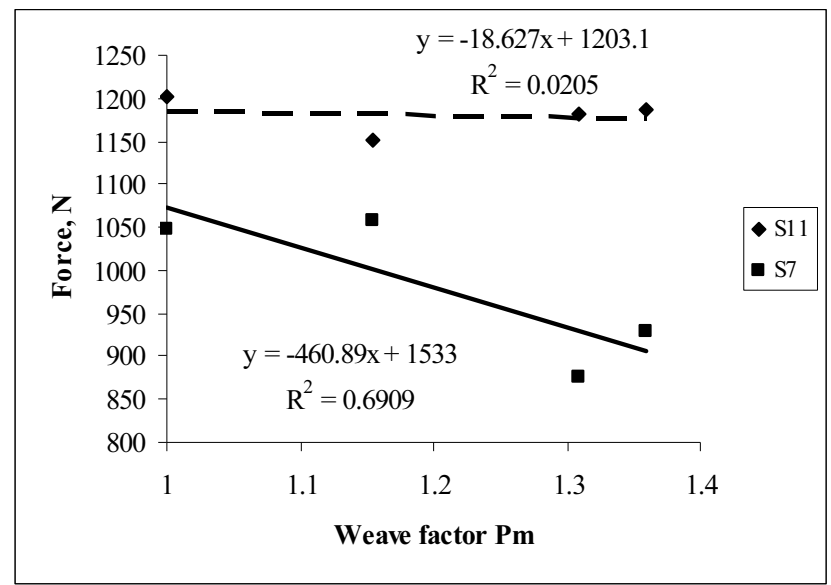

Fig. 16. Dependence of breaking force on weaving factor $P_{m}$ in weft direction

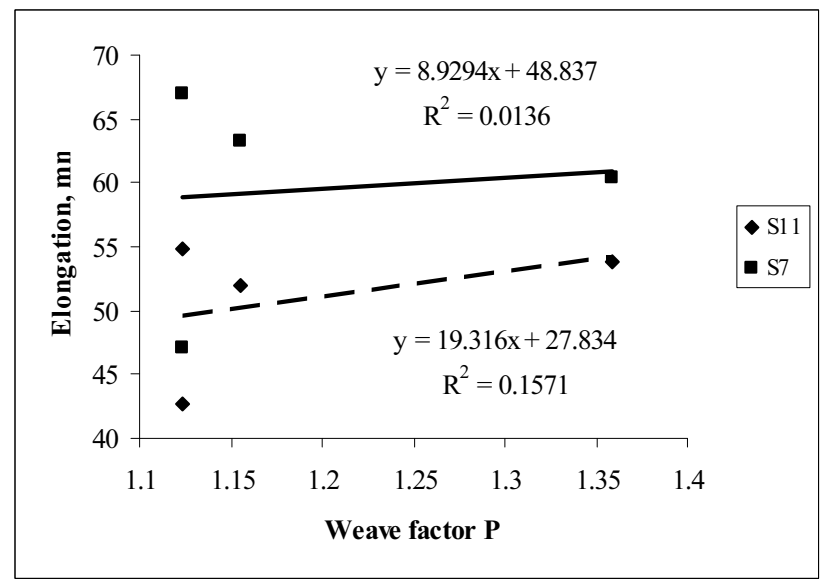

Fig. 17. Dependence of elongation on weaving factor $P$ in weft direction

The elongation in weft direction because of weave is changing in both cases, with yarn S11 and with yarn S7 in the weft. This is because weft yarns are more or less bended because of weave, and during tensile test they are straightening. Highest determination coefficient is achieved with elongation dependency on weaving factor $P_{a}$. In case of yarn S7 it is 0.84 and in case of yarn S11 it is 0.6 (See Fig. $17 \div$ Fig. 20)

Our experimental results show that there is an influence of the weave on fabric tensile properties. It is confirmed by previous works of E. Kumpikaite [13-15], in which the influence of weave on fabric, woven from twisted multifilament polyester yarn, breaking force and elongation has been investigated. She found that there is high correlation between weave factor, developed by $\mathrm{V}$. Milašius, and elongation of the fabric. $R^{2}$ of proposed equations were reaching more than 0.9 . Less important influence she had found on breaking force of the fabric, $R^{2}$ of proposed equations were reaching just 04 .

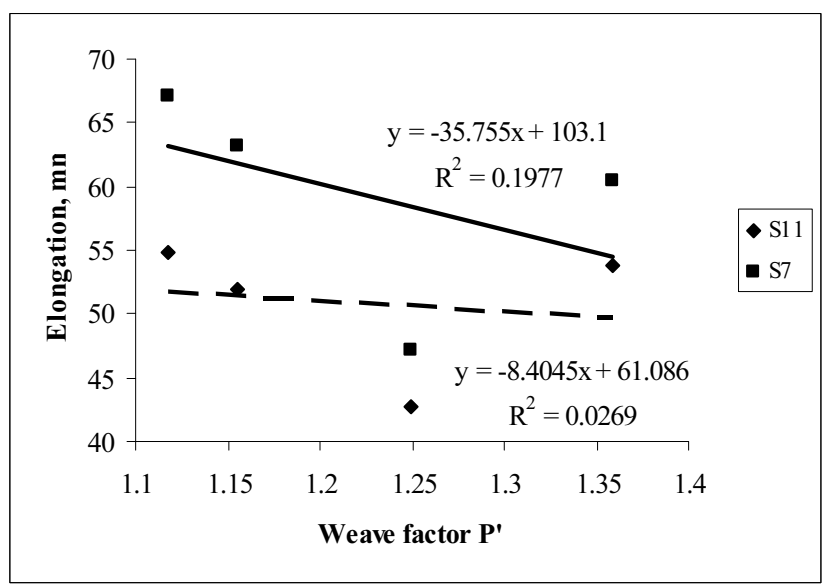

Fig. 18. Dependence of elongation on weaving factor $P^{\prime}$ in weft direction

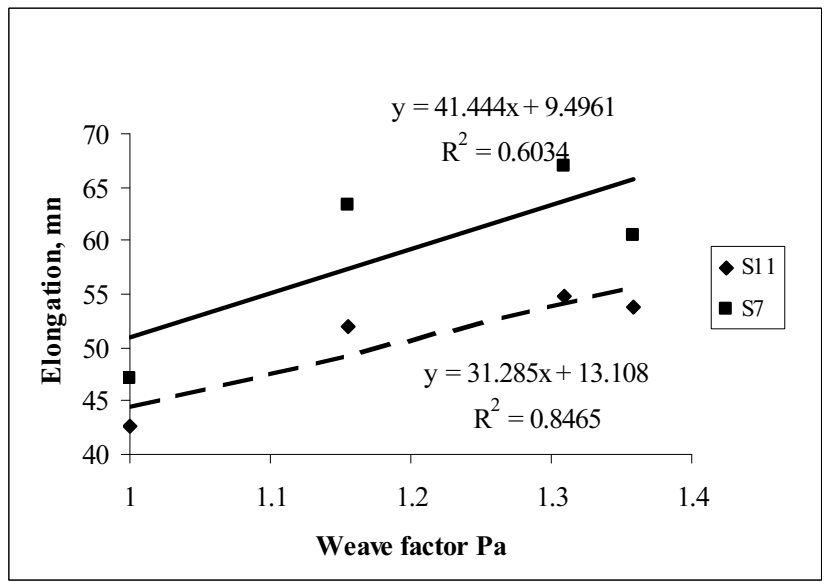

Fig. 19. Dependence of elongation on weaving factor $P_{a}$ in weft direction

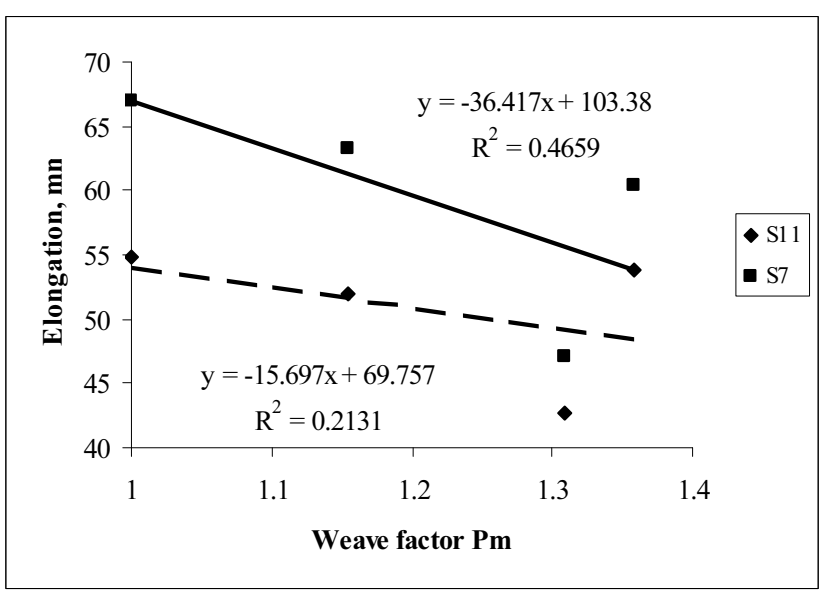

Fig. 20. Dependence of elongation on weaving factor $P_{m}$ in weft direction 
Similar influences of weave on breaking force and elongation of the fabric are described in the paper of Gabrielčič, H., Černoša, E., Dimitrovski, K. [4]. They had stated that weave has big influence on elongation of the fabric, but on the breaking force there were no important influence observed.

Banerjee at all in their paper [19] has not find any correlation between weave factors $P_{a}, P_{m}$ and fabric, woven from cotton yarn, tensile properties.

Influence of weave on tensile properties in fabrics can be different, because these properties depends not only on weave, but also on other factors, such as yarn woven into fabric structure and yarn tensile properties. Behavior of textured yarn in the fabric is completely different from spun or twisted yarn. This is because of structure of the yarn itself. Filaments in the textured yarn are looser and more crimped than in twisted yarn. This gives higher possibilities for bigger extension when force applied. Influence of yarn structure can explain why some researchers find different results of weave influence on fabric tensile properties.

\section{CONCLUSIONS}

1. The difference of breaking force and elongation at break between fabrics with S9 and S11 yarn in weft is very small. That means air pressure in the texturing jet has no influence on fabric tensile properties.

2. The second test has shown that breaking force of fabric with yarn S11 in weft is higher than of the fabric with yarn S7 in weft. The elongation at break in opposite, is higher with yarn S7 in weft. That means that structure of the yarn has great influence on fabric strength.

3. There are some tendencies of fabric breaking force dependence on weave factors $P, P_{a}, P_{m}$ and $P^{\prime}$ observed in warp direction.

4. More clear dependencies of elongation in warp direction on weave factors $P_{a}$ and $P_{m}$ were observed. The dependencies of elongation on factors $P$ and $P$ ' are week.

5 . There were observed high dependencies of breaking force on weave factors $P^{\prime}$ and $P_{m}$ in weft direction of the fabric with S7 yarn. The fabrics with yarn S11 in weft have no such tendency. This is because of different yarn structure.

6. Elongation of the fabric depends more on the factor $P_{a}$. Other weave factors have not so big influence on elongation.

\section{REFERENCES}

1. Seo, M. H., Realff, M. L., $\quad$ Pan, N., $\quad$ Boyce, M. C., Schwartz, P., Backer, S. Mechanical Properties of Fabrics Woven from Yarns Produced by Different Spinning Technologies: Yarn Failurein Woven Fabric Textile Research Journal 63 (3) 1993: pp. $123-134$.

2. Lord, P. R., Radhakrishnaiah, P. A. Comparison of Various Woven Fabric Containing Friction, Rotor and Ring Spun Cotton Yarn Fillings Textile Research Journal 58 (6) 1988: pp. 354-362.
3. Frydrich, I., Dziworska, G., Matusiak, M. Influence of Yarn Properties on the Strength Properties of Plain Weave Fabrics Fibres \& Textiles in Eastern Europe 8 (2) 2000: pp. $42-45$.

4. Gabrielčič, H., Černoša, E., Dimitrovski, K. Influence of Weave and Weft Characteristics on Tensile Properties of Fabrics Fibres \& Textiles in Eastern Europe 16 (2) 2008: pp. $45-51$.

5. Brierley, $\mathbf{S}$. Cloth Settings Reconsidered The Textile Manufacturing 79 1952: pp. 349-351, 533-537, $595-597$.

6. Peirce, F. T. The Geometry of Cloth Structure Journal of the Textile Institute 28 1937: pp. T45-196.

7. Galceran, V. Technologia del Tejido, Terrasa, 1961.

8. Newton, A. The Comparison of Woven Fabrics by Referance to Their Tightness Journal of the Textile Institute 86 1995: pp. 232-240.

9. Milašius, V. An Integrated Structure Factor for Woven Fabrics, Part I: Estimation of the Weave Journal of the Textile Institute 91-1 (2) 2000: pp. 268-276.

10. Nikolic, M. Michailovic, T., Simovic, Lj. Real Valueof Weave Binding Coeficient as a Factor of Woven Fabric Strength Fibres \& Textiles in Eastern Europe 11 2000: pp. $74-78$.

11. Milašius, A., Milašius, V. New Representation of the Fabric Weave Factor Fibres \& Textiles in Eastern Europe 16 (4) 2008: pp. $48-51$.

12. Milašius, V., Milašius, R., Kumpikaitè, E., Olšauskienė, A. Influence of Fabric Structure on Some Technological and End-use Properties Textile Research Journal 11 (2) 2003: pp. $48-51$.

13. Kumpikaite, E. The Fabric Weave's Influence on the Character of Fabric Break Materials Science (Medžiagotyra) 13 (3) 2007: pp. 245-248.

14. Kumpikaité, E., Sviderskytè, A. The Influence of Woven Fabric Structure on the Woven Fabric Strength Materials Science (Medžiagotyra) 12 (2) 2006: pp. 162-166.

15. Kumpikaite, E. Influence of Fabric Structure on the Character of Fabric Breakage Fibres \& Textiles in Eastern Europe 16 (3) 2008: pp. 48-46.

16. Abromavičius, R., Milašius, R. Dependences of Air Textured Polypropylene Yarn Properties on the Yarn Structure and Air Pressure in a Texturing Jet Fibres \& Textiles in Eastern Europe 17 (3) 2009: pp. 48-50.

17. Abromavičius, R., Milašius, R. Dependences of Polypropylene Fabric Air Permeability and Flammability on the Yarn Structure and Air Pressure in a Texturing Jet Materials Science (Medžiagotyra) 16 (2,) 2010: pp. 129-132.

18. ISO 13934-1. Textiles -Tensile Properties of Fabrics Part1: Determination of Maximum Force and Elongation at Maximum Force Using the Strip Method, 1999: 16 p.

19. Banerjee, P. K., Mishra, S., Ramkumar, T. Effect of Sett and Construction on Unaxial Tensile Properties of Woven Fabrics Journal of Engineered Fibers and Fabrics 5 (2) 2010: pp. $8-21$.

Presented at the National Conference "Materials Engineering '2010" (Kaunas, Lithuania, November 19, 2010) 